This is the last draft sent to the Editorial by the authors of the article:

M. GÓMEZ, S. F. MEDINA, P. VALLES, A. QUISPE
"Characterization by Electron Diffraction of Two Thermodynamical Phases
of Precipitation in Nb-Microalloyed Steels"
Materials Science Forum
Vol. $480-481$ (2005), Pages: $489-493$
DOI: $10.4028 /$ www.scientific.net/MSF.480-481.489
ISSN: $0255-5476$

To be published in Digital.CSIC, the Institutional Repository of the Spanish National Research Council (CSIC)

See more papers from the authors on:

$\underline{\text { http://digital.csic.es }}$

http://www.researcherid.com/rid/B-7922-2008 


\title{
Characterization by Electron Diffraction of Two Thermodynamical Phases of Precipitation in Nb-Microalloyed Steels
}

\author{
M. Gómez ${ }^{1}$, S.F. Medina ${ }^{1}$, P. Valles ${ }^{2}$ and A. Quispe ${ }^{3}$ \\ ${ }^{1}$ National Center for Metallurgical Research (CENIM), Av. Gregorio del Amo 8, \\ 28040-Madrid (Spain), E-mail: smedina@cenim.csic.es \\ ${ }^{2}$ National Institute of Aerospace Technology, INTA, Torrejón de Ardoz, Madrid, Spain \\ E-mail: vallesgp@inta.es \\ ${ }^{3}$ National University "Jorge Basadre”, Av. Miraflores s/n, University City, \\ Tacna (Peru), E-mail: abqc@unjbg.edu.pe
}

$\underline{\text { Keywords: }}$ Microalloyed steels, static recrystallisation, precipitation kinetics, TEM analysis.

\begin{abstract}
Excellent mechanical properties (high strength and toughness) of microalloyed steels are mainly caused by induced precipitation during thermomechanical treatment (TMT) and grain refinement. It has been recently found that TMT of Nb-microalloyed steels can give rise to two different kinds of precipitates, manifested by the double plateau in the statically recrystallised fraction $\left(\mathrm{X}_{\mathrm{a}}\right)$ against time curves. This work presents an electron diffraction study performed in a transmission electron microscope, equipped with an EDS Edax analytical system. Lattice parameters of a great deal of particles, smaller than $200 \mathrm{~nm}$ and with face cubic centred structure, have been measured. Frequency distribution of the values of lattice parameters shows that these are grouped in two sets whose mean values are close. Comparison of these values with those found in the literature for carbides, nitrides and carbonitrides usually present in microalloyed steels demonstrates that they are $\mathrm{Nb}$ carbonitrides with slight stoichiometric differences $\left(\mathrm{NbC}_{\mathrm{x}} \mathrm{N}_{\mathrm{y}}\right)$.
\end{abstract}

\section{Introduction}

Most hot rolled microalloyed steels are steels which contain niobium, as these have the advantage of adequate solubility at normal rolling temperatures. Vanadium presents greater solubility in austenite than niobium and its precipitation as VN, and above all as VC, occurs at very low temperatures, making it difficult to obtain sufficiently deformed austenites before the $\gamma \rightarrow \alpha$ transformation. To this end, a good part of the research work on microalloyed steels has been focused on low or medium carbon niobium steels, obtaining highly deformed austenites at the end of rolling which give rise, after the transformation, to very fine ferrite/pearlite microstructures and consequently good mechanical properties.

In steels with a $\mathrm{C}$ content of approximately $0.2 \%$, around $60 \mathrm{ppm}$ of $\mathrm{N}$, the solubility temperatures of niobium carbides and carbonitrides are not very different [1-4]. One of the consequences deriving from the above is the formation of complex carbonitrides which can be formed not as a precipitate as such but by the heterogeneous nucleation of one type of precipitates on another, forming relatively complex and coarse precipitates.

When strain induced precipitation starts, static recrystallisation is inhibited during a certain time, normally until the end of precipitation, before again advancing until recrystallisation is complete. This momentary inhibition of recrystallisation appears as a plateau on the recrystallised fraction against the logarithm of time curves [5-6]. It has been reported that some Nb-microalloyed steels 
show double precipitation (two plateaus) and it takes place when the percentages of $\mathrm{C}$ and $\mathrm{Nb}$ are such as to favour the formation of carbides rather than nitrides, a singularity typical of some microalloyed steels with $\mathrm{Nb}$ and $\mathrm{C}$ contents in excess of 0.20 mass\% [7-8]. Nevertheless the nature of these precipitates is not still clear, so in this paper the static recrystallisation is studied in a niobium microalloyed steel through the determination of recrystallised fraction against the time by means hot torsion tests. An study is made of the influence of the strain and differential thermal analysis and transmission electron microscopy (TEM) are used to assess the double precipitation and its nature .

\section{Materials and Experimental Procedure}

The steel to be studied have been manufactured by Electroslag Remelting (ESR) in a laboratory unit capable of producing $30 \mathrm{~kg}$ ingots and for their manufacturing consideration has been made of the thermodynamic activities of the slag components and of the alloying elements in order to obtain the desired composition (Table1). The ingot was forged and subsequently given a normalised treatment to reduce the band structure produced by deformation and to homogenize the microstructure.

The torsion specimens, with a gauge length of $50 \mathrm{~mm}$ and $6 \mathrm{~mm}$ in diameter, were austenitized at high temperature above to the solubility temperature, for $10 \mathrm{~min}$, and then the temperature was rapidly reduced to the testing temperature. During the test the specimens were protected by an argon atmosphere in order to prevent their oxidation. Torsion magnitudes (torque, no. of revolutions) and equivalent magnitudes (stress, strain) have been related according to Von Mises criterion [9].

The recrystallised fraction was determined at different temperatures corresponding to the austenite phase, at equivalent strain 0.35 , lower than the critical strain which leads to the start of dynamic recrystallisation, and at a strain rate of $3.63 \mathrm{~s}^{-1}$ (=1000 rev/min).

Table 1. Chemical composition (wt-\%) of the steel studied.

\begin{tabular}{|c|c|c|c|c|c|c|c|c|}
\hline $\mathrm{C}$ & $\mathrm{Si}$ & $\mathrm{Mn}$ & $\mathrm{P}$ & $\mathrm{S}$ & $\mathrm{N}$ & $\mathrm{O}$ & $\mathrm{Al}$ & $\mathrm{Nb}$ \\
\hline 0.21 & 0.19 & 1.14 & 0.023 & 0.015 & 0.0061 & 0.0046 & 0.008 & 0.058 \\
\hline
\end{tabular}

The characteristics of the precipitates were determined by transmission electron microscopy (TEM), using the carbon extraction replica technique. The study of the dissolution of precipitates was carried out by differential thermal analysis, where the heating rate of the samples was $15^{\circ} \mathrm{C} / \mathrm{min}$ and they were protected from oxidation by an argon flow of $20 \mathrm{ml} / \mathrm{min}$.

\section{Results and discussion}

The austenitization temperature was chosen taking into account that in this type of steels preliminary reheating to the deformation temperatures must guarantee total dissolution of the precipitates. In this sense, the solubility temperature for carbides, nitrides or carbonitrides, hypothetically present in this steel, is below the selected austenitization temperature of $1250^{\circ} \mathrm{C}$.

As has been mentioned, the recrystallised fraction was determined for different temperatures and strain of 0.35, respectively, using the method known as "back extrapolation"[10]. Fig. 1 shows the recrystallised fraction against time curves. When the deformation temperature was equal to or less than $1050{ }^{\circ} \mathrm{C}$, the double plateau was formed. Once the kinetics of the first precipitation (first plateau) ends and recrystallisation again continues, the second precipitation starts to occur and once this finalizes recrystallisation continues until it is complete.

The DTA curve (Fig. 2) shows three reactions. The one which occurs at a lower temperature, of endothermic nature, is the phase transformation of pearlite and ferrite into austenite (during heating), and two exothermal reactions corresponding to the dissolution of the precipitates. Comparison of the final temperatures of each reaction with the calculated solubility temperatures for niobium nitrides and carbides does not clearly show, at least not definitively, the nature of the precipitates.

Nevertheless, it seems obvious that there is a dissolution of two types of precipitates, corresponding to the formation of the two peaks respectively. 


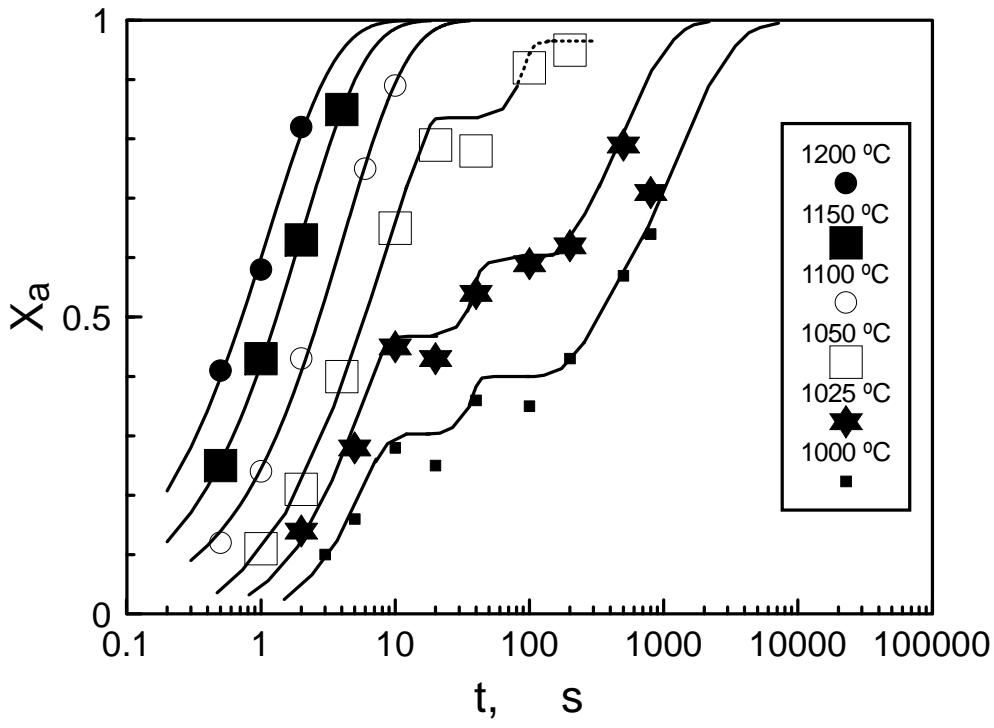

Fig. 1. Recrystallised fraction (Xa) against time (t).

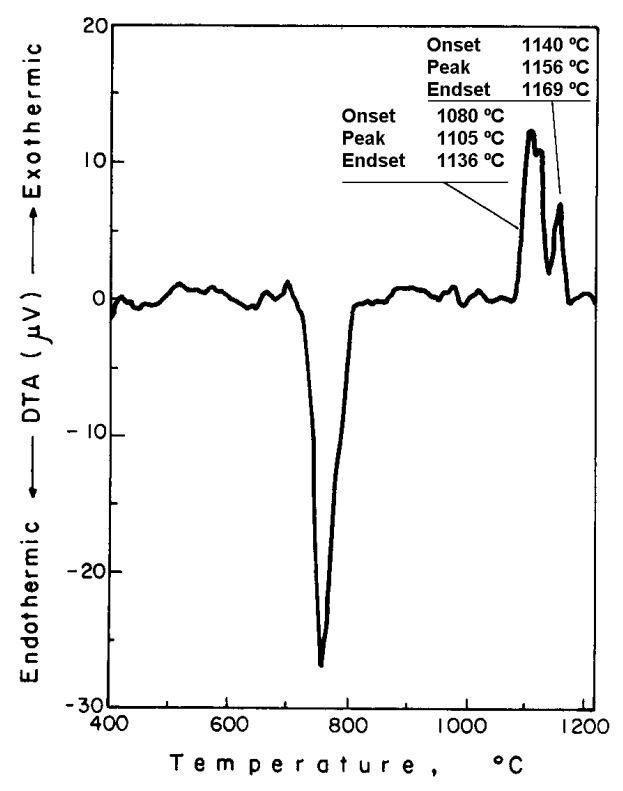

Fig. 2. DTA curve for steel used.

From the differential thermal analysis it is obviously not possible to deduce what percentages of niobium have been distributed between nitrides and carbides and therefore it is not possible to compare the solubility temperatures with the final temperatures of the two transformations. Thus, it cannot be stated with complete certainty that the precipitates are carbonitrides only and that there is not a presence of some nitrides and carbides.

Observation of the precipitates was carried out on the same specimens deformed and quenched to observe the recrystallised fraction of the austenite. In order to clarify the double precipitation (double plateau) occurred, a lot of electron diffraction analyses were performed and the lattice parameters were determined. Observations were made for the two specimens tested of the steel $\mathrm{C}$ at $1025{ }^{\circ} \mathrm{C}$, strain of 0.35 and times of $15 \mathrm{~s}$ and $100 \mathrm{~s}$, respectively. From the curve of the recrystallised fraction (Fig. 1), it is seen that the times selected are placed on the first and second plateau, respectively.

The resolution of precipitates using the carbon extraction replica technique by TEM, is shown in Fig. 3 a-b. The spectrum in Fig. 3c shows the presence of $\mathrm{Nb}$ and the lattice parameter determined from Fig. 3d reveals a f.c.c. cubic lattice with a value of $a=4.39-4.44 \AA$, which is identified, in accordance with the reference value found in the literature $[7,8]$ as a niobium carbonitride (NbCN), although it could be a nitride $(\mathrm{NbN})$ or carbide $(\mathrm{NbC})$ too, as the lattice parameter of them are similar.

The statistical study of results showed the formation of only a kind of precipitates on the first plateau and two different precipitate groups on the second plateau. In the specimen tested at $15 \mathrm{~s}$, corresponding to the first plateau, the electron energy dispersive X-ray spectrum showed the presence of $\mathrm{Nb}$ and the lattice parameter determined from electron diffraction image revealed a f.c.c. cubic lattice with a value of $a=4.39-4.44 \AA$, which is identified, in accordance with the reference value found in the literature as a niobium carbonitride, carbide or nitride. The Fig. 4 shows the distribution of lattice parameter of this type of precipitates.

In the fine precipitates at $100 \mathrm{~s}$ after deformation two series of different lattice parameter were observed. The first series presented a lattice parameter of 4.41-4.44 $\AA$, similar to the above precipitates and for the second series it was of 4.46-4.58 $\AA$ (Fig. 5). In accordance with above, the first precipitates should correspond to carbonitrides or nitrides and the second precipitates to carbides. Nevertheless, the coarser precipitates presented a lattice parameter close to $4.46 \AA$ (Fig. 6).

The last result means likely that the second precipitation is slightly heterogeneous and it is homogeneous above all. 


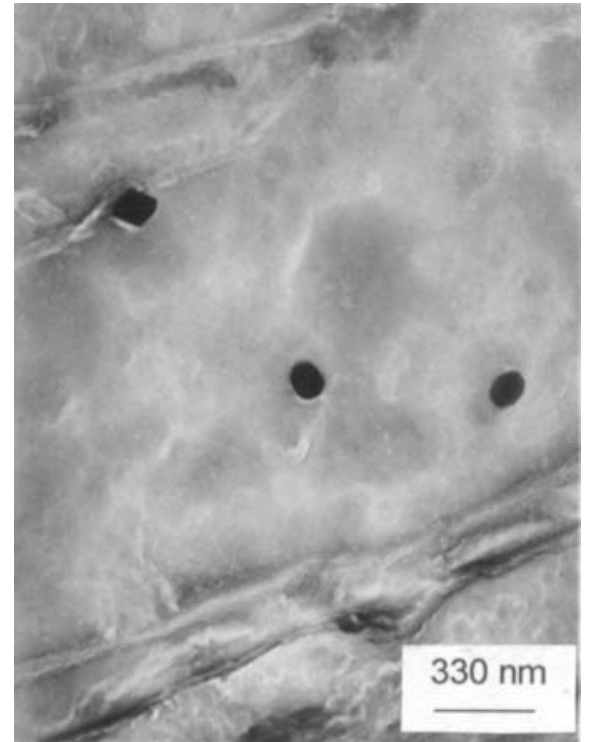

(a)

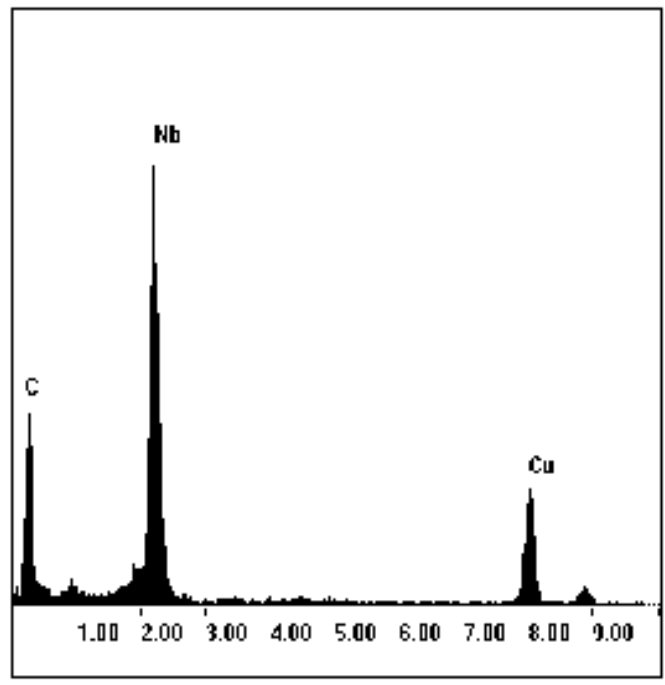

(c)

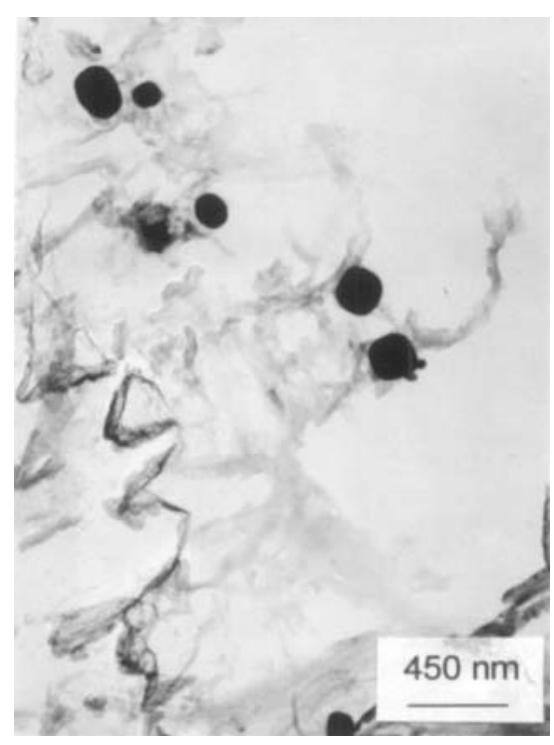

(b)

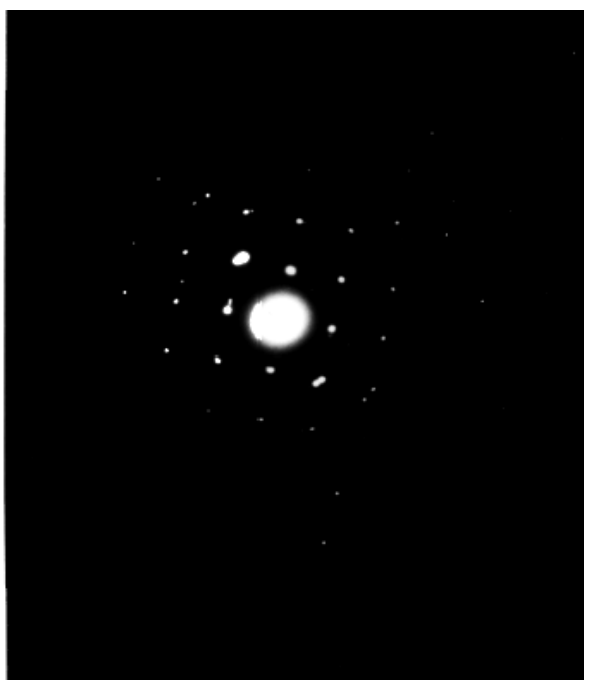

(d)

Fig 3. TEM images: (a) Image showing precipitates for specimen tested at $1025^{\circ} \mathrm{C}, \mathrm{t}=15 \mathrm{~s}$. (b) Image showing precipitates for specimen tested at $1025^{\circ} \mathrm{C} \mathrm{t}=100 \mathrm{~s}$; (c) EDAX spectrum of precipitate; (d) electron diffraction image.

\section{Conclusions}

The above results showed clearly that the second plateau is formed by a new precipitation, whose particles had a lattice parameter something bigger than those corresponding to the first precipitation (first plateau).

\section{Acknowledgements}

The authors thank the I3P Program of CSIC, financed by the European Social Fund, for the funding of the PhD grant of Eng. M. Gómez and S.E.E.U. for funding the stay at CENIM of Dr. Quispe. 


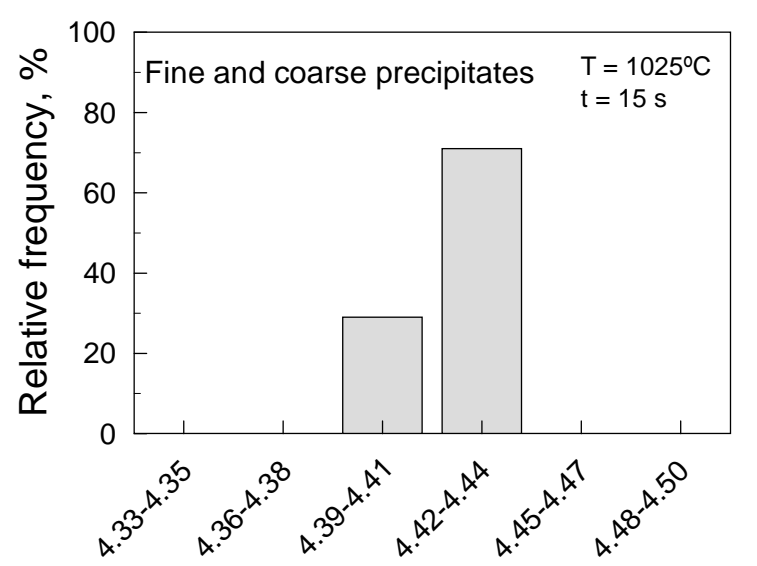

Lattice Parameter $(\AA)$

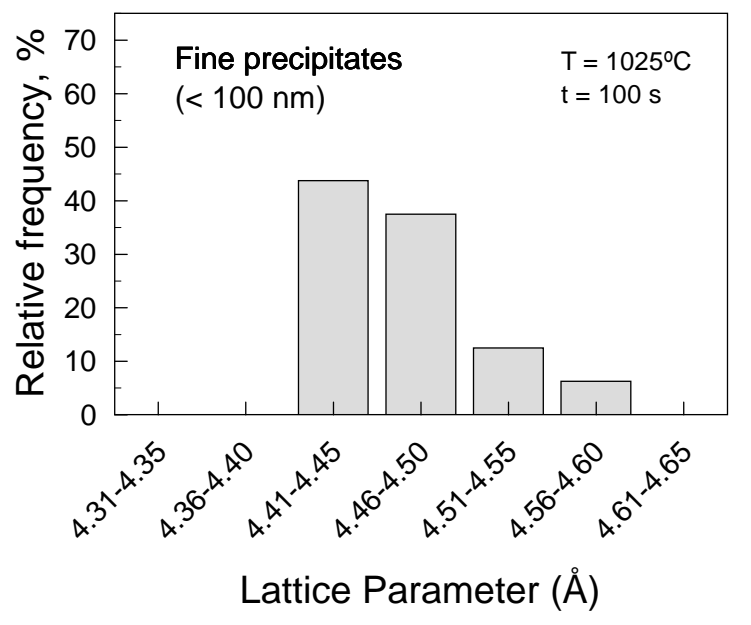

Fig. 5. Lattice parameter distribution of fine precipitates; $\mathrm{t}=100 \mathrm{~s}$.
Fig. 4. Lattice parameter distribution; $\mathrm{t}=15 \mathrm{~s}$.

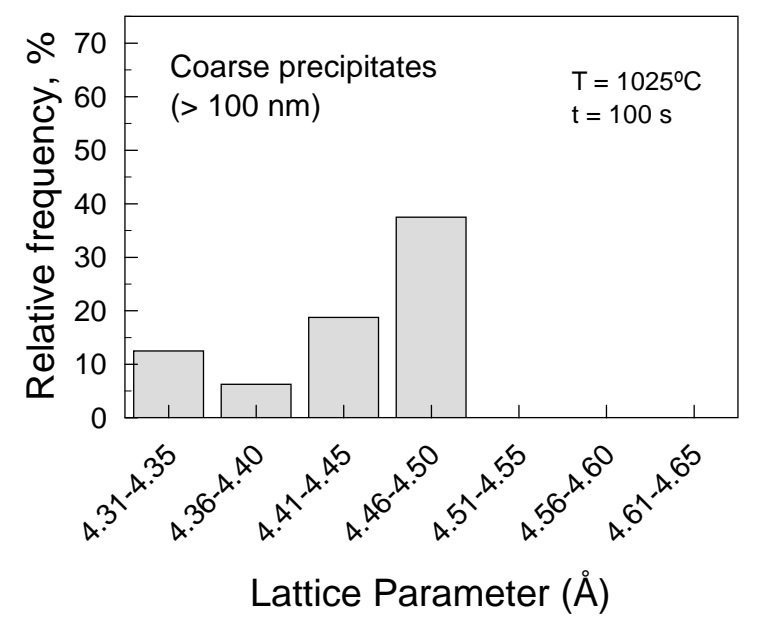

Fig. 6. Lattice parameter distribution of coarse precipitates; $\mathrm{t}=100 \mathrm{~s}$.

\section{References}

[1] K.Narita: Trans. Iron Steel Inst. Jpn. 15 (1975), p. 145

[2] E.T. Turkdogan: Iron Steelmaker, Vol. 16 (1989), p. 61

[3] P.R. Rios: Mater. Sci. Tecnol. Vol. 4 (1988), p. 324

[4] E.J. Palmiere, C. I. García and A.J. DeArdo: Metall. Trans. Vol. 25A (1994), p. 277

[5] M.J. Luton, R. Dorvel and R.A. Petkovic: Metall. Trans. Vol. 11A (1980), p. 411

[6] S.F. Medina: Journal of Materials Science, Vol. 31, (1997), p. 1487

[7] S.F. Medina, A. Quispe and M. Gómez: Mater. Sci. Technol. Vol. 19 (2003), p. 99

[8] S.F. Medina, A. Quispe: Mater. Sci. Forum, Vol. 426-432 (2003), p. 1535

[9] A. Faessel: Rev. Métall. Cah. Inf. Tech. Vol. 33 (1976), p. 875

[10] H.L. Andrade, M.G. Akben and J.J. Jonas: Metall. Trans. Vol. 14A (1983), p. 1967

[11] T. Gladman: The Physical Metallurgy of Microalloyed Steels (The Institute of Materials, London, 1997) 